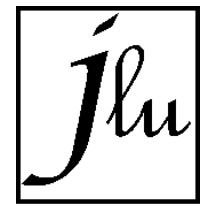

https://jurnal.univpgripalembang.ac.id/index.php/luminous

\title{
HASIL BELAJAR DAN KETERAMPILAN PROSES SAINS SISWA MELALUI PENERAPAN MODEL PEMBELAJARAN KOOPERATIF PADA PEMBELAJARAN FISIKA : SEBUAH REVIEW
}

\author{
Fernando ${ }^{1}$, Niki Dian Permana $\mathbf{P}^{2(*)}$, Susilawati ${ }^{3}$, Aldeva Ilhami ${ }^{4}$ \\ ${ }^{1}$ Program Studi Tadris IPA, Fakultas Tarbiyah dan Keguruan Universitas Islam Negeri Sultan Syarif Kasim Riau \\ fernando@students.uin-suska.ac.id \\ ${ }^{2}$ Program Studi Tadris IPA, Fakultas Tarbiyah dan Keguruan Universitas Islam Negeri Sultan Syarif Kasim Riau \\ niki.dian.permana@uin-suska.ac.id ${ }^{(*)}$ \\ ${ }^{3}$ Program Studi Tadris IPA, Fakultas Tarbiyah dan Keguruan Universitas Islam Negeri Sultan Syarif Kasim Riau \\ susilawati@uin-suska.ac.id \\ ${ }^{4}$ Program Studi Tadris IPA, Fakultas Tarbiyah dan Keguruan Universitas Islam Negeri Sultan Syarif Kasim Riau \\ aldeva.ilhami@uin-suska.ac.id
}

Received: 28 April 2020. Accepted: 25 Juni 2020. Published: Juli 2020

\begin{abstract}
Abstak
Penelitian ini bertujuan untuk menganalisis pengaruh penerapan model pembelajaran kooperative terhadap hasil belajar dan keterampilan proses sains siswa pada pembelajaran IPA-fisika. Metode penelitian yang digunakan adalah metode kuantitatif dengan menggunakan desain meta-analisis. Pengumpulan data dilakukan dengan cara mengumpulkan, merangkum, dan menganalisis artikel yang berkaitan dengan topik penelitian pada jurnal nasional terakreditasi sinta 1 hingga sinta 4. Hasil penelitian menunjukkan bahwa terdapat pengaruh model pembelajaran kooperatif terhadap peningkatan hasil belajar dan keterampilan proses sains siswa pada pembelajaran IPA-Fisika
\end{abstract}

Kata-kata Kunci: Pembelajaran Kooperatif, Hasil Belajar, Keterampilan Proses Sains, Artikel Review

\section{PENDAHULUAN \\ Pendidikan mempunyai peran yang} penting dan menentukan untuk perkembangan serta perwujudan dari setiap individu, terutama untuk pembangunan bangsa dan negara. Kualitas pendidikan yang diberikan kepada anggota masyarakat dapat meningkatkan sumber daya manusia sehingga bisa dimanfaatkan dan itu adalah bukti kemajuan suatu kebudayaan (Rizal, 2016). Era globalisasi seperti saat ini pendidikan sangat berpengaruh dalam proses perkembangan zaman. Siswa 
perlu disiapkan untuk menguasai, memahami dan mengenal ilmu pengetahuan dengan tujuan meningkatkan kualitas hidup. Upaya tersebut sudah dilakukan melalui pendidikan formal sesuai dengan UU No.20 Tahun 2003. (Darmawati, 2019).

Sejalan dengan kemajuan ilmu pengetahuan dan teknologi, manusia dituntut untuk mengembangkan kemampuan di berbagai hal, sehingga pendidikan sangatlah penting bagi manusia serta tidak dapat dipisahkan. Oleh sebab itu pendidikan harus dilaksanakan dengan sebaik mungkin agar apa yang diharapkan dapat tercapai (Hakim, 2018).

Salah satu materi yang diajarkan di sekolah adalah IImu Pengetahuan Alam (sains), materi ini mencakup kimia, biologi, fisika, astronomi serta geologi yang berupaya menerangkan hal-hal yang terjadi di alam semesta, Sains pada hakikatnya mencakup proses, produk, dan sikap. (Verawati, 2017). Fisika merupakan bagian dari sains yang memfokuskan kajiannya pada materi, energi, dan hubungan antara keduanya. Sebagai sebuah produk, fisika merupakan sekumpulan pengetahuan tentang fakta, konsep, generalisasi, prinsip, teori dan hukum fisika. Sementara sebagai suatu proses, fisika merupakan serangkaian proses ilmiah yang dilakukan dalam menenemukan pengetahuan pengetahuan tentang fisika. Dalam pembelajaran sains terdapat keterampilan khusus yang harus dimiliki sebagai bentuk sains sebagai proses, yang disebut keterampilan proses sains (KPS). Menurut Darmawan et al. (2015) "keterampilan proses sains merupakan keterampilan ilmiah yang efektif dilakukan dalam proses menemukan produk sains, termasuk fisika. Siswa akan mampu menemukan dan mengembangkan sendiri fakta dan konsep yang dipelajarinya dengan meningkatkan keterampilan proses sains yang dimiliki".

Kemampuan dasar Keterampilan proses sains sangat diperlukan dalam mempelajari dan memahami fisika. Kemampuan proses sains adalah keterampilan khusus yang digunakan oleh ilmuan untuk memahami suatu fenomena. (Hardiyanto, 2015). Keterampilan proses sains sangat perlu dikembangkan dalam proses pembelajaran fisika hal ini karena keterampilan proses sains memiliki peranan yaitu: (a) mengembangkan pikiran siswa; (b) memberi kesempatan kepada siswa untuk melakukan penemuan; (c) meningkatkan daya ingat siswa; (d) memberikan kepuasan intrisnik apabila siswa berhasil melakukan sesuatu, dan (e) membantu siswa mempelajari konsep-konsep IPA (Fatimah, 2017)

Keterampilan proses sains (KPS) meliputi kegiatan antara lain: (a) mengamati, yaitu keterampilan mengumpulkan data dan informasi dengan penerapan melalui indera berdasarkan bentuk kegiatan yang dilakuan; (b) menafsirkan, yaitu menganalogikan suatu eksperimen dengan konsep yang ada; (c) mendiskusikan, yang merupakan bentuk keterampilan agar bisa bekerjasama dengan tim untuk membehas permasalahan yang ada, (d) 
menganalisis, yaitu kemampuan menganalisis masalah berdasarkan keterampilan mengamati yang telah diikuti; (e) menyimpulkan, yaitu mengambil kesimpulan berdasarkan serangkaian kegiatan yang telah dilakukan dan setelah dilakukan analisis dan diskusi; (f) menerapkan, yaitu mengaplikasikan hasil belajar berupa informasi, kesimpulan, konsep, hukum, teori dan keterampilan; (g) mengkomunikasikan, yaitu menyampaikan perolehan hasil belajar kepada orang lain dalam bentuk gambar, tulisan, dan lain-lain (Komikesari, 2016)

Berdasarkan hasil penelitian yang dilakukan oleh Kartikasari (2011), menyatakan bahwa keterampilan proses sains siswa masih rendah serta kurang dikembangkan oleh guru. Salah satu penyebab kurang nya keterampilan proses sains siswa yaitu guru kurang memberikan kesempatan siswa untuk berpartisipasi dalam pembelajaran. Guru tetap menerapkan metode ceramah tanpa menerapkan pembelajaran yang berkaitan dengan produk dan proses pembelajaran. Keterampilan proses sains yang masih rendah berakibat pada belum adanya usaha siswa mencari informasi terkait materi yang diajarkan selain itu siswa juga kurang aktif dalam proses pembelajaran. (Rahmawati, Nugroho, \& Putra, 2014). Menyoroti terkait permasalahan diatas maka diperlukan perubahan dalam budaya pembelajaran sains saat ini. (Sofia Herrera, 2020)

Untuk membuat proses pembelajaran yang dapat merangsang siswa agar lebih aktif dalam proses pembelajaran, perlu digunakan strategi yang sesuai yaitu dengan menggunakan pendekatan, metode atau bahkan tipe yang bisa meningkatkan motivasi belajar, diminati serta menarik bagi siswa, sehingga hasil belajar siswa tidak menjadi masalah. Salah satu model yang bisa diterapkan yaitu model pembelajaran kooperatif yang diharapkan dapat meningkatkan keterampilan proses sains siswa. (Komikesari, 2016)

Model pembelajaran kooperatif atau cooperative learning merupakan model pembelajaran yang kontekstual. Pembelajaran kontekstual adalah pembelajaran yang mengaitkan konsep pelajaran yang dipelajari dengan konteks kegunaan serta hubungan materi tersebut dengan kehidupan dan cara belajar siswa itu sendiri (Yolanda, D. T., Lubis, P., Sugiarti, 2020). Model cooperative learning terdiri dari dua kata yaitu cooperative dan learning. cooperative berarti "acting together with a common purpose" belajar kelompok atau bekerjasama. Sedangkan learning adalah "the process through which experience causes permanent change in knowledge and behavior" yaitu proses pengalaman yang menyebabkan perubahan dalam perilaku serta pengetahuan. (Tambak, 2017)

Model pembelajaran kooperatif merupakan model pembelajaran yang saat ini banyak digunakan untuk mengatasi permasalahan yang ditemukan guru dalam mengaktifkan siswa, mewujudkan kegiatan belajar mengajar yang berpusat pada siswa 
(student oriented), terutama yang tidak dapat bekerja sama dengan orang lain, siswa yang agresif dan tidak peduli pada yang lain. (Sudestia Ningsih, 2016). Ada beberapa jenis dari pembelajaran kooperatif diantaranya yaitu student team achievement divisions (STAD), Jigsaw, pendekatan struktural yang meliputi thinks pair share (TPS) dan numbered head together (NHT) serta team game tournament (TGT) (Hidayah, 2019)

Model pembelajaran kooperatif ini diharapkan dapat meningkatkan keaktifan seluruh siswa dalam kelompoknya dan dalam mengikuti proses pembelajaran di sekolah. Dengan adanya peran aktif siswa dalam proses pembelajaran di sekolah maka Keterampilan Proses Sains (KPS) dan hasil belajar siswa akan meningkat pula. (Komikesari, 2016)

Penelitian sebelumnya (Dewi, 2013) "Menunjukkan bahwa model pembelajaran kooperatif disertai metode eksperimen dapat meningkatkan keterampilan proses dan hasil belajar Fisika di MAN 1 Jember tahun ajaran 2012/2013". Selanjutnya (Hasanah, 2013) "Menunjukkan bahwa model pembelajaran kooperatif TPS (Think Pair Share) dengan metode eksperimen dapat meningkatkan hasil belajar dan sikap ilmiah siswa kelas VII SMP Negeri 10 Jember. Model kooperatif tipeThink Pair Share(TPS) disertai metode eksperimen tidak hanya membuat siswa aktif dalam berpikir, bekerja sama, dan berdiskusi, tetapi juga menumbuhkan keterampilan proses sains siswa". (Riskiyah, 2015)
Berdasarkan uraian di atas penulis tertarik untuk menganalisis artikel-artikel hasil penelitian yang berkaitan dengan pengaruh penerapan model pembelajaran kooperatif dalam pembelajaran terhadap hasil belajar dan keterampilan proses sains siswa pada mata pelajaran IPA-fisika.

\section{METODE}

Metode yang digunakan pada penelitian ini adalah metode kuantitatif dengan menggunakan desain meta-analisis.

Penelitian meta-analisis adalah penelitian survei yang termasuk ke dalam penelitian deskriptif. Pengumpulan data dilakukan dengan cara mengumpulkan, merangkum, dan menganalisis artikel yang berkaitan dengan pengaruh penerapan model pembelajaran kooperatif terhadap peningkatan hasil belajar dan keterampilan proses sains siswa pada pembelajaran IPA-fisika. Artikel yang dianalisis sebanyak 15 artikel yang diperoleh dari jurnal nasional terakreditasi sinta 1 hingga sinta 4 dan Kemudian dilakukan klasifikasi berdasarkan jenis metode penelitian dan variable terikat yang digunakan..

\section{HASIL DAN PEMBAHASAN}

Hasil analisis yang telah dilakukan terhadap artikel jurnal nasional dapat dilihat pada tabel 
Tabel 1. Distribusi 15 Artikel Subjek Penelitian

\begin{tabular}{|c|c|c|c|c|}
\hline No & Peneliti & Jenis Penelitian & $\begin{array}{c}\text { Pembelajaran } \\
\text { Kooperatif }\end{array}$ & Indikator Pencapaian \\
\hline 1. & $\begin{array}{c}\text { (Rasydah Nur Tuada, } \\
\text { Gunawan, Susilawati, } \\
\text { 2017) }\end{array}$ & Quasi experiment & $\begin{array}{l}\text { Guided } \\
\text { Teaching }\end{array}$ & $\begin{array}{c}\text { Keterampilan Proses } \\
\text { Sains }\end{array}$ \\
\hline 2. & (Happy Komikesari, 2016) & Quasi experiment & $\begin{array}{c}\text { student team } \\
\text { achievement } \\
\text { divisions (STAD) }\end{array}$ & $\begin{array}{c}\text { Keterampilan Proses } \\
\text { Sains }\end{array}$ \\
\hline 3. & $\begin{array}{c}\text { (Ana Dhiqfaini Sultan, } \\
\text { 2014) }\end{array}$ & $\begin{array}{c}\text { pre-experimental } \\
\text { design }\end{array}$ & $\begin{array}{c}\text { student team } \\
\text { achievement } \\
\text { divisions (STAD) }\end{array}$ & $\begin{array}{c}\text { Keterampilan Proses } \\
\text { Sains }\end{array}$ \\
\hline 4. & $\begin{array}{c}\text { (Juraini, Muhammad } \\
\text { Taufik, Wayan Gunada, } \\
\text { 2016) }\end{array}$ & Quasi experiment & Guided Inquiry & $\begin{array}{l}\text { keterampilan Proses } \\
\text { sains dan Hasil belajar }\end{array}$ \\
\hline 5. & $\begin{array}{l}\text { (Dede Trie Kurniawan, } \\
\text { 2014) }\end{array}$ & Quasi experiment & $\begin{array}{c}\text { student team } \\
\text { achievement } \\
\text { divisions (STAD) }\end{array}$ & $\begin{array}{l}\text { Penguasaan konsep dan } \\
\text { keterampilan proses } \\
\text { sains }\end{array}$ \\
\hline 6. & $\begin{array}{l}\text { (Nurcholilah Fitri Riskiyah, } \\
\text { Indrawati, Alex Harijanto, } \\
\text { 2015) }\end{array}$ & $\begin{array}{c}\text { Penelitian } \\
\text { Tindakan Kelas } \\
\text { (PTK) }\end{array}$ & $\begin{array}{c}\text { Group } \\
\text { Investigation }\end{array}$ & $\begin{array}{l}\text { Hasil belajar dan } \\
\text { keterampilan Proses } \\
\text { sains }\end{array}$ \\
\hline 7. & $\begin{array}{c}\text { (Puri Nur'aini Agustin, } \\
\text { Albertus Djoko Lesmono, } \\
\text { Rayendra Wahyu } \\
\text { Bachtiar, 2017) }\end{array}$ & eksperimen & $\begin{array}{c}\text { student team } \\
\text { achievement } \\
\text { divisions (STAD) }\end{array}$ & Hasil Belajar \\
\hline 8. & $\begin{array}{l}\text { (Ira Nofita Sari, Masriana, } \\
\text { 2016) }\end{array}$ & eksperimen & $\begin{array}{c}\text { Think } \\
\text { Pair Share (TPS) }\end{array}$ & $\begin{array}{c}\text { Hasil belajar bedasarkan } \\
\text { gender }\end{array}$ \\
\hline 9. & $\begin{array}{l}\text { (Kholia Urwati, Nevi } \\
\text { Ernita, Yahdi, } 2019\end{array}$ & Quasi experiment & $\begin{array}{c}\text { student team } \\
\text { achievement } \\
\text { divisions (STAD) }\end{array}$ & Hasil belajar \\
\hline 10. & $\begin{array}{l}\text { (Hendri Arung Lamba, } \\
\text { 2006) }\end{array}$ & Quasi experiment & $\begin{array}{c}\text { Teams Games } \\
\text { Tournament }\end{array}$ & Hasil belajar \\
\hline 11. & Nova Irwan, Ridwan & Quasi experiment & Numbered Heads & Hasil belajar \\
\hline
\end{tabular}




\begin{tabular}{|c|c|c|c|c|}
\hline No & Peneliti & Jenis Penelitian & $\begin{array}{c}\text { Pembelajaran } \\
\text { Kooperatif }\end{array}$ & Indikator Pencapaian \\
\hline & Abdullah Sani, & & Together (NHT) & \\
\hline 12. & $\begin{array}{l}\text { (Indriyani Purba Alam, I } \\
\text { Ketut Mahardika, Rif'ati }\end{array}$ & Quasi experiment & $\begin{array}{l}\text { Team Assisted } \\
\text { Individualization }\end{array}$ & $\begin{array}{c}\text { Kompetensi Kognitif, } \\
\text { aktifitas belajar dan }\end{array}$ \\
\hline & Dina Handayani, 2016) & & (TAl) & kompetensi sikap \\
\hline 13. & $\begin{array}{l}\text { (Abd. Rasyid, Marungkil } \\
\text { Pasaribu, H. Kamaluddin, } \\
\text { 2015) }\end{array}$ & Quasi experiment & $\begin{array}{c}\text { Think Pair Share } \\
\text { (TPS) }\end{array}$ & Hasil belajar \\
\hline 14. & (Tri Ariani, 2017) & eksperimen & $\begin{array}{c}\text { Numbered Heads } \\
\text { Together (NHT) }\end{array}$ & Hasil belajar \\
\hline 15. & $\begin{array}{l}\text { (Widya Wati, Rini } \\
\text { Fatimah, 2016) }\end{array}$ & Quasi experiment & Jigsaw & $\begin{array}{c}\text { Kemampuan berpikir } \\
\text { kritis }\end{array}$ \\
\hline
\end{tabular}

Tabel 2. Jenis Pembelajaran Kooperatif

\begin{tabular}{llcc}
\hline No & \multicolumn{1}{c}{ Pembelajaran Kooperatif } & Frekuensi & Frekuensi relatif (\%) \\
\hline 1. & student team achievement divisions (STAD) & 5 & 33 \\
2. & Think Pair Share (TPS) & 2 & 13 \\
3. & Numbered Heads Together (NHT) & 2 & 13 \\
4. & Group Investigation & 1 & 7 \\
5. & Guided Teaching & 1 & 7 \\
6. & Teams Games Tournament & 1 & 7 \\
7. & Guided Inquiry & 1 & 7 \\
8. & Team Assisted Individualization (TAI) & 1 & 7 \\
9. & Jigsaw & 1 & 7 \\
\hline
\end{tabular}

Pada tabel 2 ditunjukkan bahwa 33\% pembelajaran Kooeratif tipe student team achievement divisions (STAD) lebih banyak digunakan dalam materi pembelajaran fisika. Hal ini karena model pembelajaran kooperatif tipe STAD merupakan model pembelajaran yang paling sederhana dan model ini salah satu bagian dari pembelajaran kooperatif yang menekankan pada kegiatan kerjasama kelompok sekaligus tanggung jawab perorangan untuk mencapai suatu keberhasilan dalam kegiatan pembelajaran. 
Selain itu dengan menggunakan model pembelajaran tipe student team achievement divisions (STAD) berdasarkan jurnal yang dianalisis dapat meningkatkan hasil belajar dan Keterampilan proses sains.

Tabel 3. Indikator Pencapaian

\begin{tabular}{llcc}
\hline No & \multicolumn{1}{c}{ Indikator pencapaian } & Frekuensi & Frekuensi relatif (\%) \\
1. & Hasil belajar & 9 & 45 \\
2. & keterampilan Proses sains & 6 & 30 \\
3. & Penguasaan konsep & 1 & 5 \\
4. $\quad$ Kompetensi Kognitif & 1 & 5 \\
5. & aktifitas belajar & 1 & 5 \\
6. & kompetensi sikap & 1 & 5 \\
7. $\quad$ Kemampuan berpikir kritis & 1 & 5 \\
\hline
\end{tabular}

Pada tabel 3 ditunjukkan bahwa berdasarkan hasil analisis penelitian yang telah dilakukan, kita dapat melihat bahwa model pembelajaran kooperatif dari masing-masing penelitian dapat meningkatkan hasil belajar dan keterampilan proses sains, walaupun dengan hasil perolehan yang berbeda-beda. Hal ini dapat dipengaruhi oleh beberapa faktor, yaitu faktor internal, maupun faktor eksternal. Faktor internal misalnya seperti kurang adanya motivasi dalam diri siswa tersebut sehingga siswa tidak dapat mengikuti pelajaran dengan baik. Sedangkan faktor eksternal adalah lingkungan, baik dilingkungan rumah maupun ataupun lingkungan sekolah.

Berdasarkan hasil analisis melalui perbandingan skor jurnal yang dianalisis sebelum dan sesudah tindakan pembelajaran menggunakan model pembelajaran kooperatif tipe student team achievement divisions (STAD), think pair share (TPS), numbered heads together (NHT), Group Investigation, Teamwork Skills, Guided Teaching, Teams Games Tournament, Guided Inquiry, Team Assisted Individualization (TAl) dan Jigsaw terlihat bahwa model pembelajaran kooperatif dengan menggunakan berbagai tipe dapat meningkatkan hasil belajar dan keterampilan proses sains siswa.

Hal ini memberikan bukti dengan memberikan kesempatan siswa agar dapat saling bekerja sama secara berkelompok untuk melakukan eksperimen dan penemuan akan memberikan dampak yang positif terhadapketerampilan proses sains dan mempengaruhi hasil belajar secara positif. Dalam berinteraksi siswa akan berbagi pengetahuan sehingga memperoleh pengetahuan yang merata, selain iitu juga dapat menumbuhkan rasa percaya diri siswa untuk menyelesaikan masaah sendiri 


\section{SIMPULAN}

Berdasarkan hasil penelitian diatas maka dapat disimpulkan bahwa (1) penerapan penerapan model pembelajaran kooperatif dapat meningkatkan hasil belajar, dan keterampilan proses sains siswa pada pembelajaran IPAFisika; (2) pembelajaran kooperatif yang paling banyak digunakan adalah tipe Student Team Achievement Divisions (STAD); (3) indikator pencapaian atau variable terikat yang banyak diteliti dalam penerapan pembelajaran kooperatif adalah hasil belajar.

\section{DAFTAR RUJUKAN}

Alam. (2016). Model Kooperatif Teams Games Tournament Disertai Media Kartu Soal Berbentuk Puzzle Dalam Pembelajaran Ipa Fisika Di Smp Negeri 2 Jember. Jurnal Pembelajaran Fisika, 5(2), 141-148.

Ariani. (2017). Pembelajaran Kooperatif Tipe Team Assisted Individualization ( TAI ): Dampak Terhadap Hasil Belajar Fisika Siswa. Jurnal IImiah Pendidikan Fisika, 06(2), 169-177. https://doi.org/10.24042/jipfalbiruni.v6i2.18 02

Darmawati. (2019). "Penerapan Kemampuan Metode Ekspositori Untuk Meningkatkan Motivasi Dan Kreativitas Siswa Pada Mata Pelajaran Matematika". Journal of Elemantary School (JOES), 2(1), 59.https://doi.org/10.1017/CBO9781107415 324.004

Dede Trie Kurniawan. (2012). "Model Pembelajaran Berbasis Masalah Berbantuan Website Interaktif Pada Konsep Fluida Statis Untuk Meningkatkan Penguasaan Konsep Dan Keterampilan Proses Sains Siswa Kelas XI". Jurnal Pengajaran MIPA, 19(2), 206-213.

Dinda Tsaniyyah. (2019). "Keterampilan Proses Sains Siswa Pada Pembelajaran Materi Sel Dengan Model Problem Base Learning Berbantuan Tutor Sebaya". Jurnal Phenomenon, 09(1), 21-35
Fatimah. (2017). "Analisis Pemahaman Konsep IPA Berdasarkan Motivasi Belajar, Keterampilan Proses Sains, Kemampuan Multirepresentasi, Jenis Kelamin, Dan Latar Belakang Sekolah Mahasiswa Calon Guru SD". Jurnal Inovasi Pendidikan Dan Pembelajaran, 1(1), 57-70.

Hakim. (2018). "Pengaruh Metode Demonstrasi Dan Metode Ekspositori Terhadap Hasil Belajar Mengoperasikan Sistem Pengendali Elektromagnetik (MSPEM) Di Smk Negeri 1 Lubuk Pakam". Jurnal Pendidikan Teknologi Dan Kejuruan, 20(1), 14-23.

Hidayah. (2019). "Pengaruh Model Pembelajaran Kooperatif Tipe STAD Berbantuan Peta Konsep Terhadap Peningkatan Aktivitas dan Hasil Belajar Biologi Siswa SMA Negeri 2 Siak Hulu Pada Materi Genetika". Journal of Natural Science and Integration, 2(2), 216-228.

Hardiyanto. (2015). "Pengaruh Model Pembelajaran Berbasis Masalah Dan Ekspositori Dengan Keterampilan Proses Sains Terhadap Hasil Belajar Fisika Siswa Kelas VIII". Jurnal Pendidikan Fisika Dan Teknologi, 1(4), 249-256.

Komikesari. (2016). "Peningkatan Keterampilan Proses Sains Dan Hasil Belajar Fisika Siswa Pada Model Pembelajaran Kooperatif Tipe Student Team Achievement Division". Tadris: Jurnal Keguruan Dan IImu Tarbiyah, 01(1), 1522.

Lamba. (2006). "Model Stad Dan Gaya Kognitif Terhadap Hasil Belajar Fisika Siswa Sma". Jurnal IImu Pendidikan, 13(2), 122-128.

Nova Irwan. (2015). "Efek Model Pembelajaran Kooperatif Tipe Group Investigation Dan Teamwork Skills Terhadap Hasil Belajar Fisika Nova". Jurnal Pendidikan Fisika, 4(1), 41-48.

Rasyid. (2015). "Pengaruh Model Pembelajaran Kooperatif Tipe Nht ( Numbered Heads Together ) Dan Kemampuan Awal Terhadap Hasil Belajar Siswa Pada Mata Pelajaran Fisika Di SMPNegeri 2 Poso". EJurnal Mitra Sains, 3(1), 61-68.

Rizal. (2016). "Efektivitas Penerapan Metode 
Ekspositori Berbasis Kuis Terhadap Hasil Belajar Matematika Siswa Kelas VIII MTsN Ma'rang Kabupaten Pangkep". Mapan: Jurnal Matematika Dan Pembelajaran, 4(2), $\quad$ 171-184. https://doi.org/10.24252/mapan.2016v4n2a 2

Riskiyah. (2015). "Penggunaan Model Pembelajaran Kooperatif Tipe Think Pair Share ( TPS ) Disertai Metode Eksperimen Untuk Meningkatkan Keterampilan Proses Sains Dan Hasil Belajar Fisika Siswa Kelas XI IPA 3 Sma Muhammadiyah 3". Jurnal Pendidikan Fisika, 3(4), 355-361.

Sari. (2016). "Penerapan Pembelajaran Model Kooperatif Tipe Think-Pair-Share Dalam Materi Usaha Dan Energi Ditinjau Dari Gender Siswa Kelas XI IPA Sma Negeri 1 Sungai Ambawang". Jurnal IImu Pendidikan Fisika, 1(2), 52-58.

Sultan. (2014). Jurnal Pendidikan Fisika Universitas Muhammadiyah Makassar Penerapan Model Pembelajaran Kooperatif Dengan Pendekatan Inquiry Terbimbing Untuk Meningkatkan Keterampilan Proses Sains Siswa. Jurnal Pendidikan Fisika Universitas, 4(2), 145-151.

Taufik. (2016). Pengaruh Model Pembelajaran Kooperatif Tipe STAD ( Student Team Achievement Division ) dengan Metode Eksperimen Terhadap Keterampilan Proses Sains dan Hasil Belajar Fisika pada Siswa SMA Negeri 1 Labuapi Tahun Pelajaran 2015 / 2016. Jurnal Pendidikan Fisika Dan Teknologi, II(2), 80-85.

Rasydah. (2017). "Pengaruh Model Pembelajaran Generatif Dengan Teknik Guided teaching Terhadap Keterampilan Proses Sains". Jurnal Pendidikan Fisika Dan Teknologi, 3(2), 128-136.

Urwati. (2019). "Pengaruh Model Pembelajaran Kooperatif Tipe Jigsaw Terhadap Hasil Belajar Kognitif Siswa Pada Materi Hukum Newton Kelas X MA Darul Muhajirin Praya" . Journal of Natural Science and Integration, 2(2), 203-215.

Wati. (2016). "Effect Size Model Pembelajaran Kooperatif Tipe Numbered Heads Together ( NHT) Terhadap Kemampuan Berpikir Kritis Siswa Pada Pembelajaran Fisika".
Jurnal IImiah Pendidikan Fisika, 05(2), 213-222.

https://doi.org/10.24042/jpifalbiruni.v5i2.12 1

Verawati. (2017). "Pengaruh Model Pembelajaran Ekspositori Berbantuan Scaffolding Dan Advance Organizer Terhadap Hasil Belajar Fisika Peserta Didik Kelas X". Jurnal Pendidikan Fisika

Yolanda, D. T., Lubis, P., Sugiarti. (2020). Pengaruh Model Pembelajaran Contextual Teaching And Learning (CTL) Berbantuan Alat Peraga Terhadap Pemahaman Konsep Fisika Siswa SMA. Jurnal Luminous: Riset IImiah Pendidikan Fisika, 27-36. 
